\title{
Características Físico-Mecânicas e Químicas do Couro de Caprinos Abatidos em Idades Diferenciadas 1
}

\author{
Maria Auxiliadora de Brito L. Dal Monte ${ }^{2}$, Roberto Germano Costa ${ }^{3}$, Manuel Antônio Chagas \\ Jacinto ${ }^{4}$, Ariosvaldo Nunes de Medeiros ${ }^{3}$, Francisco das Chagas Figueiredo ${ }^{5}$
}

\begin{abstract}
RESUMO - Objetivando-se analisar as características físico-mecânicas do couro de caprinos, após o curtimento, utilizaram-se 16 animais machos mestiços Alpinos, com idades a partir dos 180 dias de vida, abatidos em intervalos de 45 dias (quatro animais por abate). As peles foram curtidas e recurtidas e dos couros retiraram-se três corpos-de-prova das regiões dorsal, paleta, ventral, anca e lateral, nas direções paralelas e perpendicular ao eixo crânio-caudal, para realização dos ensaios físico-mecânicos: distensão da "flor" no lastrômetro, rasgamento progressivo, resistência à tração, análises químicas de extração de lipídios, óxido de cromo, pH e cifra diferencial. A idade do animal exerceu efeito positivo no ensaio de resistência à tração, com superioridade para os caprinos de 315 dias de vida. A região e a posição em todos animais estudados apresentaram efeito significativo no ensaio de resistência ao rasgamento progressivo, nas quatro idades, atingindo o valor de referência mínima de $80 \mathrm{kgf} / \mathrm{cm}$. A resistência do couro à distensão da "flor" dos caprinos estudados foi superior ao mínimo de $7 \mathrm{~mm}$, demonstrando grande elasticidade dos couros, sem influência de idade ou região.
\end{abstract}

Palavras-chave: ensaios físico-mecânicos, peles, resistência

\section{Physical and Mechanical Characteristics Quality of Goats Leather at Different Ages}

\begin{abstract}
This paper focuses on the analysis of goats leather to identify the physical and mechanical characteristics after toning. Sixteen male crossbred Alpine goats, with four animals from 180 days old by slaughter, were used. Slaughter intervals of 45 days were used. The skins were tanned and re-tanned, and from the breather the proofs from the dorsal, palette, ventral, hind and lateral regions, were taken, in the following directions: parallel and perpendicular to the tail-skull axis, so that the physic-mechanic studies could be performed: distention of the "flower" in the lastometer, progressive tearing; resistance to traction and chemical analyses of fat, chrome, $\mathrm{pH}$ and differential code. Animal age showed positive effect on traction resistance, with high values to goats at 315 days old. The region and position of all animals studied shower significant effect on the four reach ages, reaching the minimum reference value of $80 \mathrm{kgf} / \mathrm{cm}$. Bather resistance to distention of the "flower" from the goats were superior to the minimum of $7 \mathrm{~mm}$, showing the great elasticity of the bather, with no effect of age or region.
\end{abstract}

Key Words: physical and mechanical characteristics, goats, distention, skin

\section{Introdução}

O Brasil é o sexto maior criador de caprinos do mundo, com 10,4 milhões de cabeças, concentrando $89 \%$, ou seja, 9,2 milhões nos estados da região nordeste (BANCO DO NORDESTE, 1999).

A produção de peles de caprinos é liderada pela Ásia, principalmente pela Índia e China, que alcança 235.000 t. O Brasil produz cerca de $6.000 \mathrm{t}$, representando $1,54 \%$ da produção mundial, estimada em 390.000 t (Cavalcanti, 1988).

A pele caprina, um produto de expressão econômica, varia de 10 a $12 \%$ do valor do animal, de acordo com o porte do animal (Arbiza, 1986).

A qualidade de um couro é constatada à medida que satisfaz as exigências do fabricante de calçado, quanto às características de natureza química, mecânica e estética.

Para comercialização, a pele caprina deve atender a determinados requisitos, conforme sua utilização. A uniformidade do produto depende de um programa amplo de controle de qualidade, que engloba os fornecedores de matéria-prima e o processo de transformação da pele em couro. Hoinacki (1989) afirma que a realização de ensaios físicos é um instrumento para garantir essa qualidade, uma vez

\footnotetext{
${ }^{1}$ Parte da dissertação apresentada a UFPB pelo primeiro autor para obtenção do título de Mestre em Zootecnia.

2 Aluna do curso de Mestrado em Zootecnia CCA/UFPB, Campus de Areia-PB.

${ }^{3}$ Professor do Departamento de Agropecuária do CFT/UFPB, Campus de Bananeiras-PB. rgermano@cft.ufpb.br

4 Pesquisador do IPT - Franca, SP.

5 Técnico do CNTCC - SENAI - PB.
} 
que as propriedades físicas estão relacionadas com a composição química do couro.

As peles de caprinos curtidas sem pêlo seguem metodologia de curtimento semelhante às peles bovinas, sendo corretamente desengraxadas, por ser esta etapa a responsável pela tendência da separação das camadas termostática e reticular da derme (Briggs, 1981).

Para transformação de peles em couros, são empregados processos químicos e operações mecânicas: nos processos químicos, a água é utilizada como veículo de difusão dos produtos, denominados remolho, caleiro, desencalagem, purga, desengraxe, píquel, curtimento, neutralização, recurtimento, tingimento, engraxe e acabamento. As operações mecânicas são discriminadas como descarne, divisão, enxugamento, rebaixamento, estiragem, vácuo, lixamento, amaciamento, prensagem e medição (Thorstensem, 1976).

Maranhão (1993) preconiza que os ensaios físicos, mecânicos e químicos consistem na verificação e garantia da qualidade das empresas, visando à implantação e manutenção do controle da qualidade do produto.

Dentro dessa temática, BASF (1984) e Boccone et al. (1987) trabalharam com ensaios físico-mecânicos e químicos, executados sob padrões e normas técnicas, empregados na avaliação de couros a partir de seus comportamentos diante de carga e resistência à tração, carga e resistência ao rasgamento, resistência da flor à distensão pela esfera, determinação de óxido de cromo, determinação do $\mathrm{pH}$ da cifra diferencial e determinação de substâncias extraíveis por diclorometano (ABNT, 1988, 1989, 1990).

Diante destas informações, Boconne et al. (1987) trabalhando com 20 peles de ovinos lanados, curtidas com cromo e alumínio, identificaram a melhor região para retirada de amostras submetidas a ensaios de tração e rasgamento, coincidindo com a região que é estabelecida pelas normas técnicas.

Jacinto (1996), estudando as características anátomoestruturais da pele de ovinos das raças Ideal e Morada Nova de 1 a 4 anos, constatou que a raça e idade do animal exerceram efeito positivonos valores de resistência do couro à tração, ao rasgamento e à distensão da "flor".

Costa et al. (1998) estudaram o efeito da idade do animal na qualidade do couro de caprinos criados em regime semi-extensivo no sertão paraibano e verificaram que os couros de animais abatidos aos 150 e 300 dias de idade, considerando-se as características físicas, são de boa qualidade e adequados para fabricação de calçados.
Considerando a importância do estudo da qualidade da pele de animais em regime de confinamento, sobretudo mestiços leiteiros, por representarem considerável contingente do rebanho do nordeste brasileiro, este trabalho foi conduzido com o objetivo de avaliar a qualidade do couro de caprinos mestiços Alpinos em idades diferenciadas.

\section{Material e Métodos}

Foram utilizados caprinos mestiços Alpinos, provenientes do rebanho do setor de caprinocultura do Centro de Formação de Tecnólogos - Campus IV da UFPB, em Bananeiras, Paraíba.

O grupo de estudo foi composto por dezesseis animais machos. Foram realizados, durante o experimento quatro abates, com intervalos de 45 dias, sendo o primeiro aos 180 dias de idade, o segundo aos 225 dias, o terceiro aos 270 dias e o último aos 315 dias de vida. Os abates ocorreram no abatedouro escola do Centro de Formação de Tecnólogos.

Para as quatro diferentes idades de abate (180, 225, 270 e 315 dias), os couros dos caprinos foram avaliados em cinco regiões (dorsal, lateral, ventral, anca e paleta) e, em cada região, testaram-se as posições paralela e perpendicular ao eixo crâniocaudal. O delineamento experimental utilizado foi inteiramente casualizado, num esquema de parcela sub-subdividida, tendo como parcela as quatro idades de abate, com quatro repetições, como subparcelas as regiões do couro e, como sub-subparcelas, as posições paralela e perpendicular.

Os dados das características avaliadas foram analisados pelo teste "F" de análise de variância, a $5 \%$ de probabilidade, visando estudar a significância das interações entre os fatores estudados. Com base nos resultados, realizou-se o teste Tukey, para comparar as médias das cinco regiões do couro, e o próprio teste "F", para comparar as médias das duas posições da amostra. Os dados de idade ao abate foram submetidos à análise de regressão, utilizando-se o procedimento Proc GLM do SAS (1997).

O curtimento das peles e as análises físicomecânicas e químicas foram feitos no Centro Nacional de Tecnologia do Couro e do Calçado "Albano Franco", pertencente ao SENAI, Campina Grande - PB.

Logo após a coleta das amostras para o estudo histológico, as peles dos caprinos recém-esfolados foram conservadas em sistema de salga e secagem, conforme recomendações de Silva Sobrinho \& Jacinto (1992).

R. Bras. Zootec., v.33, n.5, p.1285-1291, 2004 
O processo de curtimento foi desenvolvido segundo metodologias de BASF (1976) e BASF (1984), seguindo as etapas de remolho, caleiro, desencalagem, purga, píquel, curtimento, basificação, neutralização, recurtimento, secagem e amaciamento.

O curtimento foi realizado em recipiente denominado fulão, medindo $100 \mathrm{~cm}$ de diâmetro por $100 \mathrm{~cm}$ de comprimento, possuindo no seu interior projeções cilíndricas de madeiras (batoques) de 10 $\mathrm{cm}$ de comprimento por $4 \mathrm{~cm}$ de diâmetro.

Posteriormente, os couros foram climatizados por 48 horas, antes da realização dos ensaios físicomecânicos. Os couros permaneceram sob refrigeração, sob temperatura de $23 \pm 2^{\circ} \mathrm{C}$ e umidade relativa de $50 \pm 5 \%$, segundo a norma NBR10455 (ABNT, 1988).

As medidas da espessura dos couros foram feitas com auxílio do equipamento espessímetro, conforme a metodologia determinada pela norma NBR2984 (ABNT, 1988), para se realizarem cálculos de resistência à tração e de rasgamento contínuo.

Os corpos-de-prova para os ensaio de tração, rasgamento e lastrômetro foram retirados no balancim - prensa hidráulica, com navalhas e facas de corte com dimensões determinadas pelas normas NBR1196 (ABNT, 1988) e NBR 1199 (ABNT, 1990).

Para o ensaio de determinação da ruptura e da distensão da "flor" do couro pelo lastrômetro, foram empregados três corpos-de-prova circulares, amostrados nas cinco regiões do couro estudadas, como estabelece a norma NBR 3307 (ABNT, 1990).

Para os ensaios de tração e rasgamento, foram utilizados três corpos-de-prova, amostrados dos couros nas cinco regiões estudadas, na direção longitudinal, paralela ao eixo crânio-caudal e três corpos-de-prova da direção transversal ao mesmo eixo.

Os ensaios de tração e rasgamento foram realizados em equipamento universal de ensaio, denominado dinamômetro (marca Kratos), com célula de carga de $500 \mathrm{~kg}$, calibrado por um laboratório pertencente à rede brasileira de calibração, como determinam as normas NBR3013 (ABNT, 1989) e NBR3015 (ABNT, 1989).

Para as análises químicas, foram selecionados ao acaso dois animais em cada abate, sendo o material retirado das regiões do "grupão", pela sua importância para a indústria, obedecendo-se à norma de preparação de amostra NBR1198 (ABNT, 1988). A análise de extração de lipídios foi feita segundo a metodologia estabelecida pela norma NBR 2969
(ABNT, 1988). As análises de pH e cifra diferencial obedeceram a metodologia prescrita pela norma NBR2987 (ABNT, 1988) e a determinação de óxido de cromo, pela NBR3014 (ABNT, 1989).

Em virtude de os parâmetros supracitados representarem apenas o comportamento do couro perante o curtimento, não foram realizadas análises estatísticas dos dados e os resultados médios encontrados foram expressos conforme determina a norma NBR1386 (ABNT, 1988).

\section{Resultados e Discussão}

Não se observou efeito significativo $(\mathrm{P}>0,05)$ da interação entre os fatores estudados pela análise de variância e, portanto, os parâmetros foram avaliados para os fatores independentemente.

No ensaio de ruptura da esfera pelo lastômetro, não foi considerada a posição de retirada do corpode-prova por ser ele circular. Por este motivo, os dados de posição, neste ensaio, não são referenciados (Tabela 1).

Por análise de regressão, obteve-se efeito quadrático $(\mathrm{P}<0,05)$ para a característica distensão, em função da idade (I), representado pela equação $\hat{\mathrm{Y}}=\mathbf{1 1 , 9} \mathbf{- 2 , 8 4} \mathbf{I} \mathbf{-} \mathbf{0 , 7 2} * \mathbf{I}^{\mathbf{2}}\left(\mathbf{R}^{2}=0,99\right)$. Embora a idade 315 dias tenha sido superior às demais, para as variáveis distensão e espessura, essa diferença não acarretou prejuízo prático, uma vez que, nas quatro idades, as médias foram acima de 7,00 $\mathrm{mm}$, valor mínimo exigido pelo PFI - Instituto de Ensaios e Pesquisas para a Fabricação de Calçados, Pirmasens, Alemanha (BASF, 1984).

Para o fator região, verificou-se que não houve diferença significativa para a variável espessura. Porém, para a variável distensão observou-se diferença significativa entre a região da paleta e as regiões lateral e ventral; entretanto, as mesmas não se diferenciaram das regiões anca e dorso.

Jacinto (1996), ao analisar couros de ovinos de um e três anos de idade, verificou médias que ultrapassaram 8,00 mm de distensão, semelhantes às deste trabalho, confirmando a relação entre espessura e distensão, o que comprova a grande elasticidade da "flor" e da camada reticular do couro nas quatro idades estudadas.

No ensaio para determinação da qualidade da estrutura fibrosa, por meio do rasgamento progressivo (Tabela 2), constatou-se que os animais apresentaram linearmente couros com maior resistência $(\mathrm{P}<0,05)$,

R. Bras. Zootec., v.33, n.5, p.1285-1291, 2004 
á medida que a idade (I) avançava, comportamento explicado pela equação de regressão $\hat{Y}=\mathbf{7 5 , 4}+\mathbf{7 , 8 1 4} * \mathbf{I}\left(R^{2}=0,96\right)$. Entretanto, as peles dos animais em todas as idades e regiões, ofereceram resistência superior às especificações para couros de boa qualidade, pois apresentaram valores médios acima do valor-referência $(80 \mathrm{kgf} / \mathrm{cm})$ estabelecido pela BASF (1984).

Estes valores também superaram os $65,86 \mathrm{kgf} / \mathrm{cm}$ registrados por Costa et al. (1998), em animais com 300 dias de idade, e ainda estão próximos aos $107,1 \mathrm{kgf} / \mathrm{cm}$ encontrados por Jacinto (1993), em animais com 3 anos de vida.

Nas variáveis espessura e carga, para o fator idade, observou-se diferença significativa dos animais de 315 dias em relação aos demais, demonstrando aumento na espessura com o avanço da idade e, conseqüentemente, exigindo-se maior carga para o rasgamento.

Para o fator região, a diferença significativa pode ser justificada pelo fato de o tanino sintético de

Tabela 1 - Médias para distensão da "flor" dos couros de caprinos, em função da idade e região

Table 1 - Means for the "flower" distention of goats leather, in function the age and region

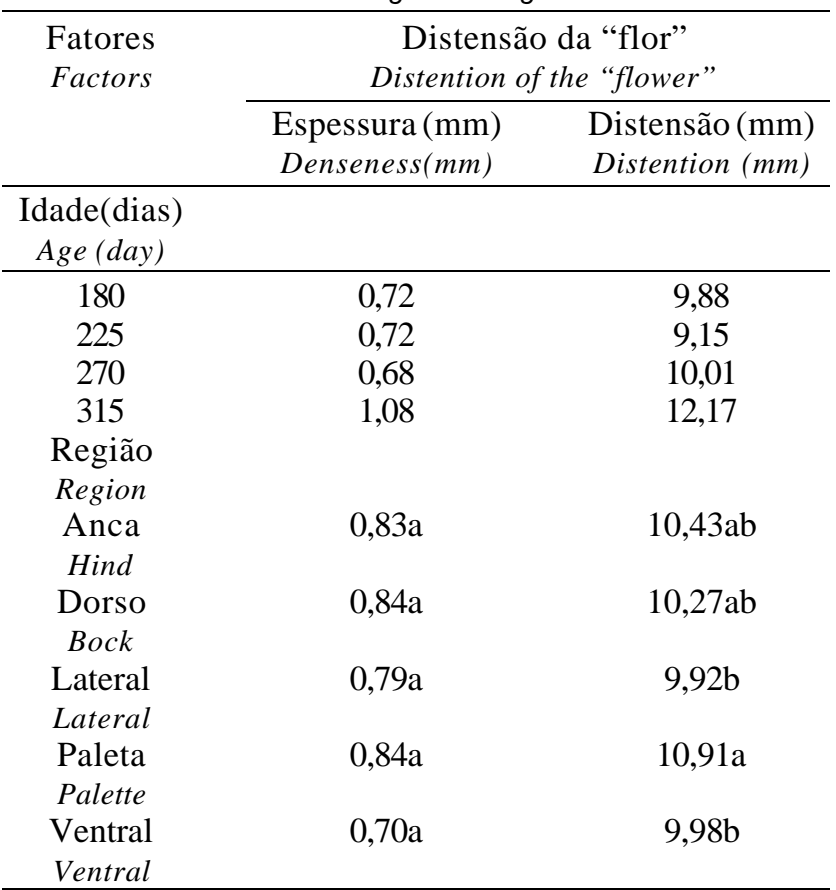

Médias seguidas de mesma letra, na coluna, não diferem entre si pelo teste Tukey $(P>0,05)$.

Means followed by the same letter, within a column, are not different $(P>$.05) by Tukey test.

R. Bras. Zootec., v.33, n.5, p.1285-1291, 2004 substituição usado no recurtimento ter apresentado melhor absorção nas regiões dorsal e lateral que são as mais ricas em fibras de colágeno.

Para o fator posição, não houve diferença $(\mathrm{P}>0,05)$ no ensaio de resistência ao rasgamento progressivo.

A análise de regressão no ensaio de resistência à tração (Tabela 3) apresentou apenas efeito cúbico, em função da idade dos animais. Entretanto, esse efeito não se ajusta ao modelo experimental, além de ser um comportamento de difícil justificativa biológica. Portanto, a resistência média das peles foi de $222,5 \mathrm{kgf} / \mathrm{cm}^{2}$, valor superior à especificação mínima para esse ensaio, de $200 \mathrm{kgf} / \mathrm{cm}^{2}$ (BASF, 1984).

Neste mesmo teste, a posição horizontal diferiu $(\mathrm{P}<0,05)$ da vertical, quanto à carga e à resistência. Por esta razão, a norma MB3013 (ABNT, 1989) determina a retirada dos corpos-de-prova nas duas posições.

Para o fator região, as regiões lateral e dorso diferiram estatisticamente das regiões anca e paleta. A pele não apresenta textura e espessura uniformes, em todas as suas regiões, o que justifica sua divisão em diferentes zonas, visando racionalizar o processo de curtimento, bem como a obtenção de produtos com maior uniformidade. A zona do "grupão", onde as regiões dorsal e lateral estão inseridas, é a parte da pele mais rica em fibras colágenas e apresenta melhor entrelaçamento das fibras. Por outro lado, a zona dos flancos ou ventre é mais pobre em material colágeno e tem um entrelaçamento mais fraco que as outras zonas, além de os ângulos de entrelaçamento de suas fibras serem maiores, resultando em um tecido mais flácido.

As informações contidas na Tabela 3, correspondentes à análise de resistência à tração, comprovam a influência da idade em relação à espessura e à carga. Quanto à posição do eixo crânio-caudal da pele, verificou-se maior resistência na posição horizontal. Por conseguinte, a região ventral mostrou-se menos espessa, enquanto a paleta e a anca ficaram abaixo do mínimo especificado para resistência à tração $\left(200 \mathrm{kgf} / \mathrm{cm}^{2}\right)$ (BASF, 1984).

O comportamento dos couros no ensaio de tração, para as duas posições, apresentou diferença significativa, demonstrando que a disposição dos feixes de fibras de colágeno exerceu influência em cada uma delas, confirmando a necessidade desses ensaios serem realizados com amostras nas duas posições. Parry et al. (1978) e Craig et al. (1987), estudando a organização ultraestrutural da pele dos mamíferos, 
com especial atenção à sua função mecânica, notaram que as propriedades físicas estavam relacionadas com o diâmetro e o comprimento das fibras de colágeno e sua distribuição ou posição na pele. Pilotto \& Filosi (1977) notaram que o diâmetro das fibras de colágeno está relacionado com o tamanho do corpo do animal.

Observou-se que o conteúdo médio de lipídios remanescentes do couro de caprino, nos quatro grupos etários, após o desengraxe, foi de $9,75 \%$, valor inferior ao encontrado por Jacinto (1996), em ovinos da raça Ideal $(12,22 \%)$ (Tabela 4). BASF (1984) apresenta valores analíticos, para couros vacum, entre 5 e $11 \%$ de substâncias extraíveis em diclorometano, que são limites importantes para se evitar o surgimento da eflorescência da graxa.

À medida que a idade dos animais avançou, o conteúdo de lipídios diminuiu, passando de 10,97 para
$8,62 \%$. A maior quantidade de lipídios no couro de caprinos aos 180 dias de idade está associada à elevada densidade de glândulas sebáceas anexas aos folículos pilosos.

Na fabricação de calçados, a colagem do couro é prejudicada quando há índices de lipídios acima de $10 \%$, podendo ocorrer má adesão do acabamento.

A partir de medidas quantitativas do teor de cromo combinado, analisa-se a transformação das peles em material estável e imputrecível, suportando, sem encolha, temperaturas elevadas durante a montagem do calçado, comprovando o fenômeno de reticulação, que resulta no aumento da estabilidade do colágeno, que deve atingir o valor mínimo de 2,5\% (BASF, 1984).

O resultado da determinação do conteúdo de cromo combinado das amostras dos couros, nas quatro idades dos caprinos estudados foi, em média,

Tabela 2 - Médias para rasgamento progressivo dos couros de caprinos, em função da idade, posição e região

Table 2 - Means of tearing progressive of goats leather, in function the age, position and region

\begin{tabular}{|c|c|c|c|}
\hline \multirow{3}{*}{$\begin{array}{l}\text { Fatores } \\
\text { Factors }\end{array}$} & \multicolumn{3}{|c|}{$\begin{array}{l}\text { Rasgamento progressivo } \\
\text { Tearing progressive }\end{array}$} \\
\hline & Espessura (mm) & Carga (kgf) & Resistência (kgf/cm) \\
\hline & Denseness $(\mathrm{mm})$ & Load $(\mathrm{kgf})$ & Resistance $(\mathrm{kgf} / \mathrm{cm})$ \\
\hline \multicolumn{4}{|l|}{$\begin{array}{c}\text { Idade (dias) } \\
\text { Age (day) }\end{array}$} \\
\hline 180 & 0,71 & 6,22 & 82,55 \\
\hline 225 & 0,72 & 7,76 & 93,31 \\
\hline 270 & 0,69 & 8,92 & 96,27 \\
\hline 315 & 1,08 & 11,15 & 107,61 \\
\hline \multicolumn{4}{|l|}{ Posição } \\
\hline $\begin{array}{c}\text { Horizontal } \\
\text { Horizon }\end{array}$ & $0,78 \mathrm{a}$ & $8,94 \mathrm{a}$ & $94,76 \mathrm{a}$ \\
\hline Vertical & $0,82 \mathrm{a}$ & $8,09 \mathrm{a}$ & $95,11 \mathrm{a}$ \\
\hline \multirow{2}{*}{\multicolumn{4}{|c|}{$\begin{array}{l}\text { Vertical } \\
\text { Região }\end{array}$}} \\
\hline & & & \\
\hline \multicolumn{4}{|l|}{ Region } \\
\hline $\begin{array}{l}\text { Anca } \\
\text { Hind }\end{array}$ & $0,93 \mathrm{a}$ & $7,84 \mathrm{a}$ & $80,74 \mathrm{c}$ \\
\hline $\begin{array}{l}\text { Dorso } \\
\text { Bock }\end{array}$ & $0,90 \mathrm{a}$ & $9,76 \mathrm{a}$ & $111,71 \mathrm{a}$ \\
\hline $\begin{array}{l}\text { Lateral } \\
\text { Lateral }\end{array}$ & $0,88 \mathrm{a}$ & 7,93 a & $99,19 b$ \\
\hline Paleta & $0,86 \mathrm{a}$ & $7,48 \mathrm{a}$ & $92,21 b c$ \\
\hline $\begin{array}{l}\text { Palette } \\
\text { Ventral }\end{array}$ & $0,87 \mathrm{a}$ & $9,57 \mathrm{a}$ & $90,82 b c$ \\
\hline Ventral & & & \\
\hline
\end{tabular}

Médias seguidas de mesma letra para o fator posição e para o fator região, na coluna, não diferem entre si pelo teste $F$ e pelo teste de Tukey $(P>0,05)$, respectivamente.

Means followed by the same letter of factor position and region, within a column, are not different by $F$ test and Tukey test $(P>.05)$, respectively.

R. Bras. Zootec., v.33, n.5, p.1285-1291, 2004 
Tabela 3 - Médias para o ensaio físico-mecânico de resistência à tração dos couros de caprinos, em função da idade, posição e região

Table 3 - Means of resistance to traction of goats leather, in function the age, position and region

\begin{tabular}{|c|c|c|c|}
\hline \multirow[t]{2}{*}{$\begin{array}{c}\text { Fatores } \\
\text { Factors }\end{array}$} & \multicolumn{3}{|c|}{$\begin{array}{l}\text { Tração } \\
\text { Traction } \\
\end{array}$} \\
\hline & $\begin{array}{c}\text { Espessura }(\mathrm{mm}) \\
\text { Denseness }(\mathrm{mm})\end{array}$ & $\begin{array}{l}\text { Carga (kgf) } \\
\text { Load (kgf) }\end{array}$ & $\begin{array}{c}\text { Resistência }\left(\mathrm{kgf} / \mathrm{cm}^{2}\right) \\
\text { Resistance }\left(\mathrm{kgf} / \mathrm{cm}^{2}\right)\end{array}$ \\
\hline \multicolumn{4}{|l|}{ Idade (dias) } \\
\hline \multicolumn{4}{|l|}{ Age (days) } \\
\hline 180 & 0,72 & 15,34 & 214,03 \\
\hline 225 & 0,74 & 17,43 & 241,94 \\
\hline 270 & 0,70 & 13,47 & 198,36 \\
\hline 315 & 1,18 & 25,94 & 225,58 \\
\hline Posição & & & \\
\hline Position & & & \\
\hline $\begin{array}{l}\text { Horizontal } \\
\text { Horizon }\end{array}$ & $0,85 a$ & $21,25 \mathrm{a}$ & $252,05 a$ \\
\hline $\begin{array}{l}\text { Vertical } \\
\text { Vertical } \\
\text { Região }\end{array}$ & $0,81 \mathrm{a}$ & $14,84 b$ & $187,90 \mathrm{~b}$ \\
\hline Region & & & \\
\hline $\begin{array}{l}\text { Anca } \\
\text { Hind }\end{array}$ & $0,99 a$ & 17,69ab & $182,26 \mathrm{c}$ \\
\hline $\begin{array}{l}\text { Dorso } \\
\text { Back }\end{array}$ & $0,90 \mathrm{ab}$ & $21,21 \mathrm{a}$ & $240,28 \mathrm{a}$ \\
\hline Lateral & $0,77 \mathrm{bc}$ & $20,42 \mathrm{a}$ & $252,70 \mathrm{a}$ \\
\hline $\begin{array}{l}\text { Lateral } \\
\text { Paleta } \\
\text { Palette }\end{array}$ & $0,79 b c$ & $15,35 b$ & $192,85 b c$ \\
\hline $\begin{array}{l}\text { Ventral } \\
\text { Ventral }\end{array}$ & $0,72 \mathrm{c}$ & $15,57 \mathrm{~b}$ & $231,80 \mathrm{ab}$ \\
\hline
\end{tabular}

Médias seguidas de mesma letra para o fator posição e para o fator região, na coluna não diferem entre si pelo teste $F$ e pelo teste de Tukey $(P>0,05)$, respectivamente. Means followed by the same letter of factor position and region, within a column, are not different by $F$ test and Tukey test $(P>.05)$ respectively.

$5,60 \%$ (Tabela 4), percentual superior a 4,03\% observado por Jacinto (1996), em ovinos das raças Morada Nova e Ideal.

Os valores de $\mathrm{pH}$ dos couros de caprinos estudados foram, em média, 3,93 $\pm 0,03$ e a cifra diferencial $(0,27$ \pm 0,01). Como os valores orientativos são $3,5 \mathrm{pH}$ e $<0,70$ cifra diferencial (BASF, 1984), esses couros não apresentaram excesso de ácidos livres.

$\mathrm{O} \mathrm{pH}$ e a cifra diferencial do extrato aquoso do couro moído medem a concentração de íons na solução. A acidez excessiva provoca a degradação da cadeia protéica, pela hidrólise ácida, diminuindo a resistência do couro.

As análises físico-químicas dos parâmetros envolvidos no processamento do couro poderão garantir a qualidade de um artigo, pois estas medidas quantitativas refletem o comportamento do couro perante o controle de qualidade.

\section{Conclusões}

Os caprinos apresentaram peles mais resistentes em função do avanço da idade dos animais, nos testes de distensão da "flor" e rasgamento progressivo. A resistência do couro dos caprinos à distensão da "flor" foi superior ao mínimo de $7 \mathrm{~mm}$, demonstrando grande elasticidade, sem influência da idade ou região. As idades, regiões e posições demonstraram superioridade aos valores mínimos recomendados de $80 \mathrm{kgf} / \mathrm{cm}$, para o teste de resistência ao rasgamento progressivo. 
Tabela 4 - Médias e desvios-padrão dos ensaios químicos para os couros dos caprinos, em função da idade

Table 4 - Means and standard desviation of chemical trials of goats leather, in function of age

\begin{tabular}{ccccc}
\hline $\begin{array}{c}\text { Idade (dias) } \\
\text { Age (days) }\end{array}$ & $\begin{array}{c}\text { Lipídio (\%) } \\
\text { Lipid (\%) }\end{array}$ & $\begin{array}{c}\text { Óxido de Cromo (\%) } \\
\text { Chrome (\%) }\end{array}$ & $\mathrm{pH}$ & $\begin{array}{c}\text { Cifra diferencial } \\
\text { Differential code }\end{array}$ \\
\hline 180 & $10,97 \pm 1,07$ & $5,67 \pm 0,16$ & $3,94 \pm 0,02$ & $0,26 \pm 0,01$ \\
225 & $9,87 \pm 1,59$ & $5,76 \pm 0,14$ & $3,96 \pm 0,03$ & $0,28 \pm 0,01$ \\
270 & $9,57 \pm 1,76$ & $5,75 \pm 0,05$ & $3,96 \pm 0,02$ & $0,27 \pm 0,02$ \\
315 & $8,62 \pm 0,54$ & $5,23 \pm 0,08$ & $3,88 \pm 0,06$ & $0,27 \pm 0,02$ \\
\hline Média (Mean) & $9,75 \pm 1,24$ & $5,60 \pm 0,10$ & $3,93 \pm 0,03$ & $0,27 \pm 0,01$ \\
\hline
\end{tabular}

\section{Literatura Citada}

ARBIZA, S. I.A. Productos caprinos. In: Produccion de caprinos. México: AGT Editora, 1986. p.105-181.

ASSOCIAÇÃO BRASILEIRA DE NORMAS TÉCNICAS-ABNT. Climatização de materiais usados na fabricação de calçados e correlatos. NBR10455, MB1123. Rio de Janeiro, 1988. 5p. Preparação de amostras de couro para análise química. NBR11034, MB1198. Rio de Janeiro, 1988. 2p.

Couros - Determinação de substâncias extraíveis com dicloro-metano $\left(\mathbf{C H}_{\mathbf{2}} \mathbf{C l}_{\mathbf{2}}\right)$, NBR 11030, MB2969. Rio de Janeiro, 1988. 2p.

. Expressão dos resultados de análises químicas em couros, NBR11040, MB1386. Rio de Janeiro, 1988. 2p. Couros - Determinação da medida de espessura, NBR11052, MB2984. Rio de Janeiro, 1988. 3p. Couros - Determinação do pH e da cifra diferencial do pH de um extrato aquoso. NBR11057, MB2987. Rio de Janeiro, 1988. 2p.

Couros - Determinação da resistência à tração e alongamento. NBR11041, MB3013. Rio de Janeiro, 1989. 3p.

Couros - Determinação de óxido crômico $\left(\mathbf{C r}_{\mathbf{2}} \mathbf{O}_{\mathbf{3}}\right)$, NBR11054, MB3014. Rio de Janeiro, 1989. 4p. . Couros - Determinação da força de rasgamento progressivo. NBR11055, MB3015. Rio de Janeiro, 1989. 4p. . Couro - Determinação da ruptura e da distensão da flor - Lastômetro, MB3307. Rio de Janeiro: 1990. 4p. .Corte de corpos-de-prova em couro, NBR 11035 , NB1199. Rio de Janeiro, 1990. 1p.

BANCO DO NORDESTE. Programa para o desenvolvimento sustentável da ovino-aprinocultura na Região Nordeste. Fortaleza, 1999. 61p.

BASF. Pieles de animales pequeños: curtición, recurtición, tintura, engrase y acabado. Ludwigshafen: 1976. 41p.

BASF. Vademécum para el técnico en curtición. 2.ed. Ludwigshafen, 1984. 441p.

BOCCONE, R.I.; FONTANA, J.; BELLO, M. El desengrase de cueros ovinos. Monografias Tecnológicas, n.17, p.1-11, 1987.

BRIGGS, P.S. Gloving, clothing and especial leathers. London: Tropical Development and Research Institute, 1981. 166p.

CAVAlCANTI, G.; SILVA, R.C. Aspectos da caprinoovinocultura na região Nordeste: tecnologia, produção e comercialização. Recife: SUDENE/DSP/AAB, 1988. 36p.
COSTA, R.G.; DAL MONTE, M.A.B.L.; GROTA, M. et al. Efeito da idade do animal na qualidade do couro de caprinos criados em regime semi-extensivo. In: REUNIÃO ANUAL DA SOCIEDADE BRASILEIRA DE ZOOTECNIA, 27. 1998, Botucatu. Anais... Botucatu: Sociedade Brasileira de Zootecnia, 1998. p.355-358.

CRAIG, A.S., EIKENBERRY, E.F.; PARRY, D.A.D. Ultrastructural organization of skin: classification on the basis os mechanical role. Connective Tissue Research, S.1., v.16, p.213-223, 1987.

HOINACKI, E. Peles e couros. 2.ed. Porto Alegre: CPF de Artes Gráficas, 1989. 320p.

JACINTO, M.A.C. O couro caprino produzido no Brasil. Jaboticabal: Universidade Estadual Paulista, 1993. 45p. Monografia - Universidade Estadual Paulista, 1993.

Características anátomo-estruturais da pele e do couro de ovinos lanados e deslanados. Jaboticabal: UNESP , 1996 - 92 p. Dissertação (Mestrado em Zootecnia).

MARANHÃO, M. Série ISO 9000. Rio de Janeiro: Quality, 1993. $144 \mathrm{p}$

PARRY, D. A. D.; BARNES, G.R.G.; GRAIG, A.S. A comparison of the size distribution of collagen fibrils in connective tissue as a function of age and a possible relationship bet ween fibril size distribution and mechanical properties. Proceedings Royal Society, S.1., v.203, p.305-321, 1978.

PILOTTO, F.; FILOSI, M. Reloationshipbetween collagem fibril diameters and body size. Cellular Tissue Research, S.1., v.182, p.119-131, 1977.

STATISTICAL ANALYSES SYSTEM - SAS. User's guide: statistic. 2.ed. Cary: 1997.

SILVA SOBRINHO, A.G.; JACINTO, M.A.C. Peles ovinas. 1.ed. Jaboticabal: FUNEP, 1992. 33p.

THORSTENSEN, T.C. Practical leather technology. 2.ed. Huntington: Robert \& Krieger Publishing, 1976. 294p. 